\title{
Synthesis and Characterization of Monometallic (Ag, Cu) and Bimetallic Ag-Cu Particles for Antibacterial and Antifungal Applications
}

\author{
Marta Paszkiewicz, ${ }^{1}$ Anna Gołąbiewska, ${ }^{2}$ Lukasz Rajski, ${ }^{3}$ Ewelina Kowal, ${ }^{3}$ Agnieszka \\ Sajdak, ${ }^{3}$ and Adriana Zaleska-Medynska ${ }^{1}$ \\ ${ }^{1}$ Department of Environmental Technology, Faculty of Chemistry, University of Gdansk, 80-308 Gdansk, Poland \\ ${ }^{2}$ Department of Chemical Technology, Faculty of Chemistry, Gdansk University of Technology, 80-233 Gdansk, Poland \\ ${ }^{3}$ Laundry and Dry Cleaning Center Eko-Styl Rental Sp. Z o. o. Sp.k., 37-300 Lezajsk, Poland \\ Correspondence should be addressed to Anna Gołąbiewska; annagolabiewska@o2.pl
}

Received 13 November 2015; Accepted 27 January 2016

Academic Editor: Xuping Sun

Copyright ( 2016 Marta Paszkiewicz et al. This is an open access article distributed under the Creative Commons Attribution License, which permits unrestricted use, distribution, and reproduction in any medium, provided the original work is properly cited.

In this paper, the experimental studies are concerned with the effect of the synthesis parameters on the formation of monometallic $\mathrm{Ag}$ and $\mathrm{Cu}$ nanoparticles (NPs). We consider the synthesis strategies verification for the bimetallic core-shell and alloy particles preparation. It was successfully obtained by chemical reduction method. The obtained colloidal solution is characterized by the transmission electron microscopy (TEM) with energy-dispersive X-ray spectroscopy (EDX) data, UV-Vis spectra, particle size distribution, and zeta potential. This work presents a comprehensive overview of experimental studies of the most stable colloidal solutions to impregnate fabrics that will exhibit a bactericidal and fungicidal activity against Candida albicans, Escherichia coli, and Staphylococcus aureus.

\section{Introduction}

In the recent years, metal nanoparticles have attracted much attention owing to their excellent high activity against many species of bacteria and fungi [1-3]. These metal nanoparticles revealed the new optical, electrical, and mechanical properties and higher reactivity due to their high surface to volume ratio, distinct from those of the corresponding metallic bulk materials. Furthermore, bimetallic composite nanoparticles, composed of two different metal elements, are of a greater interest than monometallic nanoparticles from both scientific and technological points of view. The structure of bimetallic nanoparticles is defined by the distribution modes of the two elements and can be oriented in random alloy, alloy with an intermetallic compound, cluster-in-cluster, and core-shell structures, leading to enhanced applications, compared to monometallic nanoparticles [4-7].

Silver nanoparticles (Ag NPs) are nontoxic and have a high electrical and thermal conductivity and strong oxidation properties but the hindrance to its use in commercial products is of high cost. Monodisperse colloidal solution of silver nanoparticles is generally synthesized by chemical reduction [8-10], electrochemical [11-13], photochemical [14-16], and sonochemical methods [17-19], and also using a pulsed laser [20-22]. As an alternative, researchers examined copper nanoparticles ( $\mathrm{Cu} \mathrm{NPs}$ ), which are less expensive and present similar properties [23-26]. However, the preparation of the $\mathrm{Cu}$ NPs is problematic due to their easy oxidation. Therefore, many studies are required to develop simple shape-controlled synthesis methods of $\mathrm{Ag} / \mathrm{Cu}$ bimetallic nanoparticles $(\mathrm{Ag} / \mathrm{Cu}$ NPs) [27-31]. Currently, the developed synthesis methods for $\mathrm{Ag}$ and $\mathrm{Cu}$ NPs include a chemical reduction, thermal decomposition, polyol, laser ablation, and an electron beam irradiation. Among these methods, the chemical reduction is the most preferred because of the simplicity and the low costs. The chemical reduction provides the ability of size and distribution control by optimizing the experimental parameters. 
Many researchers have investigated the Ag/Cu NPs but not so much attention has been paid to examine the influence of synthesis parameters on size/shape of the NPs. Tsuji et al. [32] reported polyol synthesis of $\mathrm{Ag} / \mathrm{Cu}$ NPs with the use of silver nitrate $\left(\mathrm{AgNO}_{3}\right)$ and copper acetate $\mathrm{Cu}(\mathrm{OAc})_{2} \cdot \mathrm{H}_{2} \mathrm{O}$ in ethylene glycol. They found out that the $\mathrm{Ag} / \mathrm{Cu}$ alloy or $\mathrm{Ag} / \mathrm{Cu}$ core $\mathrm{Cu}$ shell particles can be prepared by the change of the $(\mathrm{Ag}) /(\mathrm{Cu})$ molar ratio or the reaction time. It was also established that $\mathrm{Cu}$ component of the $\mathrm{Ag} / \mathrm{Cu}$ core Ag shell nanoparticles had a higher antioxidization character than that of the $\mathrm{Cu}$ or $\mathrm{Cu}$ core $\mathrm{Ag}$ shell particles. Kim et al. [4] obtained Ag/Cu NPs by oleylamine-based thermal decomposition process using $\mathrm{AgNO}_{3}$ and copper acetylacetonate $\left(\mathrm{Cu}\left(\mathrm{C}_{5} \mathrm{H}_{7} \mathrm{O}_{2}\right)_{2}\right)$ as metal precursors. It was observed that the electron transfer from $\mathrm{Cu}$ to $\mathrm{Ag}$ within bimetallic NPs allows oxidation for better resistance than monometallic $\mathrm{Cu}$ NPs. Zain et al. [33] achieved Ag/Cu NPs by chemical reduction in the presence of chitosan using microwave heating. They noticed that $\mathrm{Ag} / \mathrm{Cu}$ bimetallic NPs demonstrated a higher antibacterial activity against Bacillus subtilis and Escherichia coli than $\mathrm{Ag}$ or $\mathrm{Cu}$ monometallic NPs. The modified pulsed wire evaporation method was introduced to prepare $\mathrm{Ag} / \mathrm{Cu}$ core-shell NPs in one-step process by Kim et al. [34]. The samples were not oxidized for over six months and were stable up to about $200^{\circ} \mathrm{C}$ in the air.

In this work, monometallic, bimetallic silver and copper nanoparticles were obtained by the chemical reduction method. For the first time the effect of the silver precursor's type (silver nitrate, silver sulfate, and silver citrate), copper precursor (copper chloride, copper nitrate, copper sulfate, and copper acetate), the type of reducing agent (sodium borohydride, hydrazine, and ascorbic acid), and the type of stabilizing agent (polyvinylpyrrolidone (PVP), polyethylene glycol (PEG), cetyltrimethylammonium bromide (CTAB), and citric acid) on stability of Ag NPs and $\mathrm{Cu}$ NPs was systematically examined. In this work the extensiveness of experimental studies on the synthesis parameters effect on the formation monometallic Ag and Cu NPs has been demonstrated. We consider the verification of synthesis strategies for the preparation of bimetallic core-shell and alloy particles. This paper is concerned with a comprehensive overview of experimental studies selection of the most stable colloidal solutions to impregnate fabrics that will exhibit a bactericidal and fungicidal activity. Moreover, for the very first time we present the correlations between antimicrobial, antifungal efficiency and the type of the bimetallic particles.

\section{Materials and Methods}

2.1. Materials and Instruments. Silver nitrate (V), silver sulfate (VI), copper chloride, copper nitrate (V), and copper sulfate (VI) provided by Sigma Aldrich and copper acetate received from Avantor Performance Materials Poland S.A. were used as the precursors for the preparation of $\mathrm{Ag}, \mathrm{Cu}$, and $\mathrm{Ag} / \mathrm{Cu}$ nanoparticles. Silver citrate was prepared in our laboratory (Section 2.3). Reagents needed to synthesize silver citrate such as sodium citrate (III) and silver carbonate were provided by Sigma Aldrich and citric acid, sodium hydroxide, and acetic acid were received from POCh. Sodium borohydride $99 \%$, hydrazine monohydrate $98 \%$, and ascorbic acid were provided by Aldrich and used as the reducing agents. CTAB, PEG, and PVP were received from Sigma Aldrich and were used as the stabilizers. Isopropanol and distilled water were used as the reaction media. All the chemicals were used without the further purification.

The samples diffuse reflectance UV-Vis absorption spectra were obtained with the use of a spectrophotometer UV-Vis Thermo model: Nicolet Evolution 220. Water and water-isopropanol solution in volume ratio $1: 3$ were used as reference samples. The Zetasizer Nano ZS (Malvern Instruments Ltd., UK) was used for the dynamic light scattering measurements (DLS). A He-Ne laser was used as the light source with a wavelength $\lambda=661 \mathrm{~nm}$. The intensity of light was scattered at $90^{\circ}$ angle. The measurements allowed determining the hydrodynamic diameter of the particles in suspension (i.e., the effective diameter) or the multimodal particle size distribution. TEM analysis was performed on the FEI Tecnai F20 X-Twin microscope with the spectrometer EDX (r-TEM SUTW, EDAX). The samples were observed under bright-field (BF STEM) and SE mode (detection of secondary electrons, information about the morphology of the surface). The samples were suspended in ethanol (99.8\%) and were put into an ultrasonic bath (InterSonic IS-1K) for 5 seconds. Then, the drop $(4 \mu \mathrm{L})$ was collected and placed on a copper mesh coated with a carbon layer with holes (Plano, type Lacey $\mathrm{Cu} 400 \mathrm{mesh}$ ). The solvent was evaporated at the room temperature.

\subsection{Testing for Antibacterial Activity and Efficacy on Textile} Products. The JIS L 1902:2002 absorption method is designed to quantitatively test the ability of textiles that have been treated with this antibacterial agent to prevent a bacterial growth and to kill bacteria, for over an 18-hour period of contact. This method is based on the quantitative determination of the potential effect and activity of functionalized samples, by the direct contact with a suspension of bacterial cells. For each prepared strain of $1.0 \pm 0.3 \times 10^{5}$ cells $/ \mathrm{mL}$ inoculum using nutrient broth diluted with water of 1:20 (v:v). Samples of fabrics controlled and treated with antimicrobial substances $15 \times 15 \mathrm{~mm}$ have been sterilized UV, next placed in sterile tubes, and inoculated with an inoculum volume of $0.2 \mathrm{~mL}$. The samples were incubated for $18 \mathrm{~h}$ at $37^{\circ} \mathrm{C}$ (bacteria) and $30^{\circ} \mathrm{C}$ (fungi). For each strain used the control samples after 0 time and control and test samples after $18 \mathrm{~h}$ of incubation cultures were performed to determine the number of microorganisms. To each tube containing the fabric sample $2 \mathrm{~mL}$ of sterile saline containing $0.2 \%$ Tween 80 was added. The contents thoroughly mixed on the vorteks have done serial dilutions in sterile saline. From the mixture baseline and serial dilution $1 \mathrm{~mL}$ was taken. Next, the seeds were performed on blood agar nutrient by flood method. After $48 \mathrm{~h}$ of incubation at $37^{\circ} \mathrm{C}$ (bacteria) and $30^{\circ} \mathrm{C}$ (fungi) the cells have been counted. In order to carry out the judgment of test effectiveness, the growth value was calculated according to the following equation:

$$
F=M_{b}-M_{a}
$$


When the growth value is more than 1.5 , the test is judged to be effective, and when the growth value is 1.5 or less, the test is judged to be ineffective. When the test is ineffective, a retest is necessary. When the quantitative test has been effective, the bacteriostatic activity value should be calculated in accordance with the following equation:

$$
S=M_{b}-M_{c}
$$

and the bactericidal activity according to

$$
L=M_{a}-M_{c},
$$

where $F$ is the growth value and $S$ and $L$ are the bacteriostatic and bactericidal activity values, respectively. $M_{a}$ is the average of common logarithm of the number of living bacteria on the test pieces immediately after inoculation of inoculum on standard cloth. $M_{b}$ is the average of common logarithm of the number of living bacteria on the test pieces after $18 \mathrm{~h}$ incubation. $M_{c}$ is the average of common logarithm of the number of living bacteria on the test pieces after $18 \mathrm{~h}$ incubation on antibacterial treated sample. Traditionally, bacteriostatic means prevention of multiplication of bacteria without destroying them, whereas the bactericidal effect implies forthright killing of the organisms $[35,36]$.

2.3. Preparation of Silver Citrate. Sodium citrate (III), citric acid, and silver carbonate were dissolved in demineralized water. After three days supernatant was collected in a conical flask. Then sodium hydroxide and hydrazine monohydrate were added to the above solution. The solution has changed the color to brown-green with a black precipitate. The solution was filtered on the crimp filter. The resulting precipitate was washed in $6 \%$ acetic acid. The filter with precipitate was placed in a porcelain crucible and calcined. The crucible was weighted before and after calcination. The amount of pure silver was a mass difference. Silver with concentration of $C=$ $413 \mathrm{ppm}$ in $5 \mathrm{dm}^{3}$ has been received. The citric acid was used as a stabilizer.

2.4. Preparation of Monometallic Nanoparticles Ag, Cu. The solutions containing silver (nanoAg or ions $\mathrm{Ag}^{+}$) and copper (nanoCu or ions $\mathrm{Cu}^{2+}$ ) were received in water solution and in an organic solvent: isopropanol in volume ratio $3: 1$ (water: isopropanol). To stabilize the colloidal solutions the surfactants such as CTAB, PEG, and PVP were used. Concentration of silver and copper was $50 \mathrm{ppm}$. Characteristics of obtained solutions is presented in Table 1 (Supplementary Materials) (see Supplementary Material available online at http://dx.doi.org/10.1155/2016/2187940). The components of each solution are marked with a cross. The research included a preparation of 224 samples with a different composition. The influence of following parameters was investigated: metal precursor, reducing agent, stabilizer, and stability of obtained samples. All possible combinations have been tested. Based on the results, the optimal conditions for synthesis of bimetallic system were selected.
2.5. Preparation of Bimetallic Nanoparticles Ag/Cu. To obtain bimetallic nanoparticles, silver citrate and copper acetate as a metal precursors, water-isopropanol solution with volume ratio $3: 1$ as a solvent, PVP as a stabilizer, and sodium borohydride $\left(\mathrm{NaBH}_{4}\right)$ as a reducing agent were used. Depending on the route of synthesis, various types of bimetallic nanoparticles have been achieved. In order to obtain $\mathrm{Ag} / \mathrm{Cu}$ alloy single-step reduction and to obtain the core-shell nanoparticles a double-step reduction has been used.

\section{Results and Discussion}

\subsection{The Effect of Synthesis Parameters on the Formation Monometallic Ag NPs, Cu NPs}

3.1.1. UV-Vis. To obtain silver and copper nanoparticles, various metal precursors were used: silver nitrate (V) $\mathrm{AgNO}_{3}$, silver sulfate (VI) $\mathrm{AgSO}_{4}$, silver citrate $\mathrm{C}_{6} \mathrm{H}_{5} \mathrm{Ag}_{3} \mathrm{O}_{7}$, copper chloride $\mathrm{CuCl}_{2}$, copper nitrate $(\mathrm{V}) \mathrm{Cu}\left(\mathrm{NO}_{3}\right)_{2}$, copper sulfate (VI) $\mathrm{Cu}\left(\mathrm{SO}_{4}\right)_{2}$, and copper acetate $\mathrm{C}_{4} \mathrm{H}_{6} \mathrm{CuO}_{4}$. The use of silver citrate and copper acetate led to achieving nanoparticles which have exhibited a high stability over time, whereas the application of other metal precursors caused the aggregation of the obtained nanoparticles. Absorption spectra of the specific silver precursors were performed (Figure 1 Supplementary Materials). Characteristic peak from ionic silver is observed at $220 \mathrm{~nm}$. For colloid silver, prepared from precursors silver nitrate and silver sulfate, the maximum absorbance is noticeable at $414 \mathrm{~nm}$ (Figures 1(a) and 1(b) Supplementary Materials). In the case of silver citrate application as a precursor, the peak shift values 400 and $403 \mathrm{~nm}$ are shown (Figure 1(c) Supplementary Materials). Shift towards lower wavelength is the result of the small particles size in the colloidal system [37]. The surface plasmon resonance band (LSPR) with the peak at $\sim 400 \mathrm{~nm}$ indicates that nanoparticles with size from 10 to $100 \mathrm{~nm}$ were obtained [38]. Chen and Yeh [39] stated the plasmon band of the colloidal Ag is shifted to red (longer wavelength). These observations reflect the formation of larger Ag particles. Moreover, a sharp SPR indicates the formation of spherical nanoparticles [40]. The absorption of spectra UV-Vis of specific copper precursors was also performed (Figure 2 Supplementary Materials). Due to the existence of LSPR, copper nanoparticles exhibit a characteristic peak at a wavelength of 500-700 nm. The location of plasmon absorption bands of specific metal nanoparticles depends on the size and shape of the nanostructures. A characteristic peak in the obtained colloidal copper solution was not observed. This is because of a very low metal concentration $(C=50 \mathrm{ppm})$ in the solution. In order to confirm the above the aqueous solution of a copper higher concentration (200 ppm) was prepared. $\mathrm{C}_{4} \mathrm{H}_{6} \mathrm{CuO}_{4}$ was used as a precursor. To stabilize the samples, the PVP stabilizer was applied. For the reduction process, a strong reducing agent $\mathrm{NaBH}_{4}$ was used. Figure 2(e) in the Supplementary Materials shows the absorption spectrum, which presented a fairly wide characteristic peak of the copper nanoparticles, prepared with $\mathrm{C}_{4} \mathrm{H}_{6} \mathrm{CuO}_{4}$, in the range of $500-700 \mathrm{~nm}$ with a maximum in $652 \mathrm{~nm}$. Shin et al. 
TABLE 1: Preparation conditions and characteristics of monometallic colloids.

\begin{tabular}{|c|c|c|c|c|}
\hline Sample label & Preparation conditions & Particles size $(\mathrm{nm})$ & Zeta potential $(\mathrm{mV})$ & Color of solution \\
\hline NanoAg18 & $\mathrm{AgNO}_{3}, \mathrm{NaBH}_{4}, \mathrm{PVP}, \mathrm{H}_{2} \mathrm{O}$ & 110.5 & -2.02 & Pale yellow \\
\hline NanoAg30 & $\mathrm{AgNO}_{3}, \mathrm{NaBH}_{4}, \mathrm{PVP}, \mathrm{H}_{2} \mathrm{O}$-isop. & 229.8 & -1.2 & Pale yellow \\
\hline NanoAg50 & $\mathrm{AgSO}_{4}, \mathrm{NaBH}_{4}, \mathrm{PVP}, \mathrm{H}_{2} \mathrm{O}$ & 72 & -2.24 & Yellow \\
\hline NanoAg62 & $\mathrm{AgSO}_{4}, \mathrm{NaBH}_{4}, \mathrm{PVP}, \mathrm{H}_{2} \mathrm{O}$-isop. & 151 & -1.7 & Yellow \\
\hline NanoAg82 & $\mathrm{Ag}_{3} \mathrm{C}_{6} \mathrm{H}_{5} \mathrm{O}_{7}, \mathrm{NaBH}_{4}, \mathrm{PVP}, \mathrm{H}_{2} \mathrm{O}$ & 58.2 & -2.2 & Yellow \\
\hline NanoAg83 & $\mathrm{Ag}_{3} \mathrm{C}_{6} \mathrm{H}_{5} \mathrm{O}_{7}, \mathrm{~N}_{2} \mathrm{H}_{4}, \mathrm{PVP}, \mathrm{H}_{2} \mathrm{O}$ & 215.2 & -3.11 & Yellow \\
\hline NanoAg94 & $\mathrm{Ag}_{3} \mathrm{C}_{6} \mathrm{H}_{5} \mathrm{O}_{7}, \mathrm{NaBH}_{4}, \mathrm{PVP}, \mathrm{H}_{2} \mathrm{O}$-isop. & 40.1 & -38.4 & Yellow \\
\hline NanoAg95 & $\mathrm{Ag}_{3} \mathrm{C}_{6} \mathrm{H}_{5} \mathrm{O}_{7}, \mathrm{~N}_{2} \mathrm{H}_{4}, \mathrm{PVP}, \mathrm{H}_{2} \mathrm{O}$-isop. & 395.1 & -2.66 & Yellow \\
\hline NanoCu156 & $\mathrm{Cu}\left(\mathrm{NO}_{3}\right)_{2}, \mathrm{~N}_{2} \mathrm{H}_{4}, \mathrm{PEG}, \mathrm{H}_{2} \mathrm{O}$-isop. & 244.6 & -0.463 & Brown \\
\hline NanoCu208 & $\mathrm{C}_{4} \mathrm{H}_{6} \mathrm{O}_{4} \mathrm{Cu}, \mathrm{N}_{2} \mathrm{H}_{4}, \mathrm{PEG}, \mathrm{H}_{2} \mathrm{O}$ & 103.4 & -0.0619 & Brown \\
\hline NanoCu219 & $\mathrm{C}_{4} \mathrm{H}_{6} \mathrm{O}_{4} \mathrm{Cu}, \mathrm{NaBH}_{4}, \mathrm{PEG}, \mathrm{H}_{2} \mathrm{O}$-isop. & 8.7 & -0.463 & Brown \\
\hline NanoCu220 & $\mathrm{C}_{4} \mathrm{H}_{6} \mathrm{O}_{4} \mathrm{Cu}, \mathrm{N}_{2} \mathrm{H}_{4}, \mathrm{PEG}, \mathrm{H}_{2} \mathrm{O}$-isop. & 243 & -17.4 & Light brown \\
\hline NanoCu222 & $\mathrm{C}_{4} \mathrm{H}_{6} \mathrm{O}_{4} \mathrm{Cu}, \mathrm{NaBH}_{4}$, PVP, $\mathrm{H}_{2} \mathrm{O}$-isop. & 19.7 & -22.2 & Light brown \\
\hline NanoCu223 & $\mathrm{C}_{4} \mathrm{H}_{6} \mathrm{O}_{4} \mathrm{Cu}, \mathrm{N}_{2} \mathrm{H}_{4}, \mathrm{PVP}, \mathrm{H}_{2} \mathrm{O}$-isop. & 262.7 & -0.104 & Brown \\
\hline
\end{tabular}

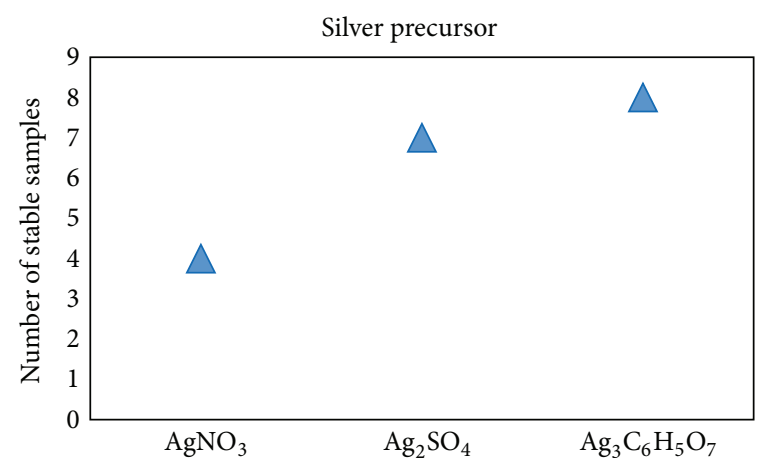

(a)

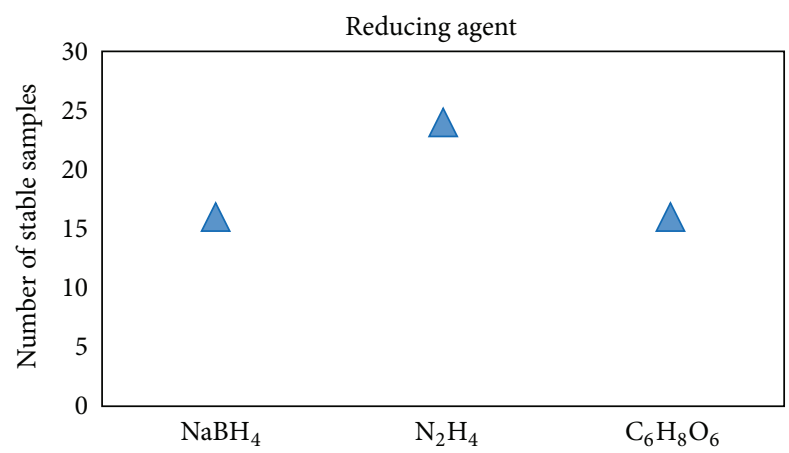

(c)

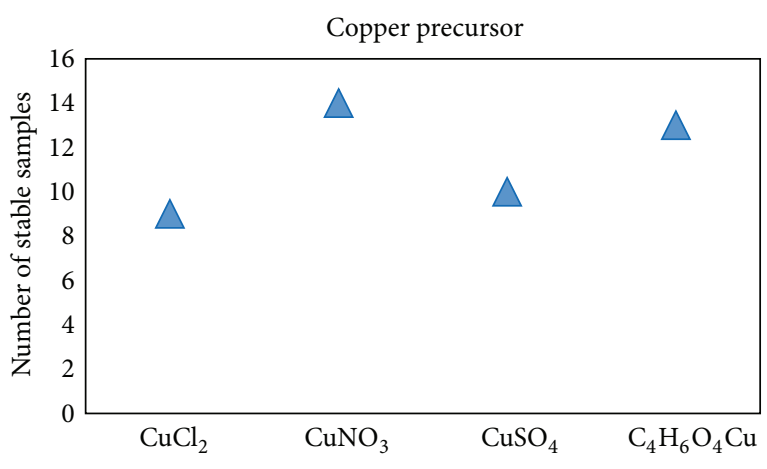

(b)

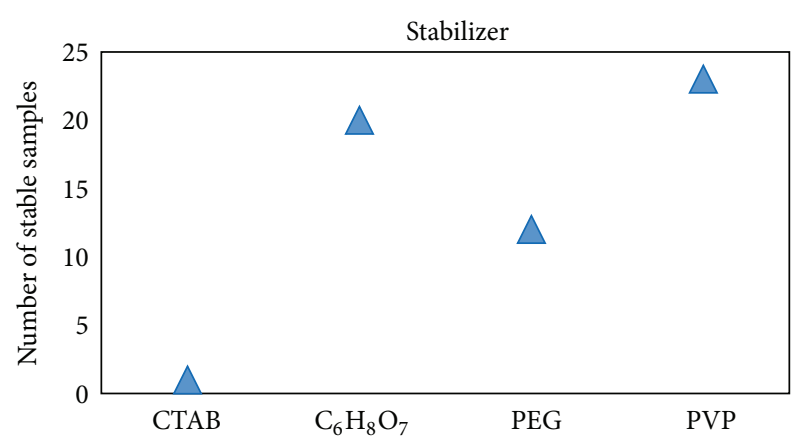

(d)

FIGURE 1: The effect of type of metal precursors, type of reducing agent, and type of stabilizers on the stability of silver and copper colloids: (a) silver precursors, (b) copper precursors, (c) reducing agent, and (d) stabilizers (stable samples: precipitate was not observed after 3 months of storage).

[41] revealed that the characteristic wavelength and intensity of the LSPR spectra are extremely sensitive to interparticle distance and dielectric environment of the particles. They observed one of a single peak with a maximum in $615 \mathrm{~nm}$ for copper nanoparticles. Similar result was also observed by Tilaki et al. [42]; they confirm the maximum of the optical excitation at around $609 \mathrm{~nm}$, which is also related to the surface plasmon resonance of copper nanoparticles in water.
3.1.2. Particle Size Distribution and Zeta Potential. The particle size distribution obtained through DLS analysis for the most stable over time samples was performed (see details in Figures 3 and 4 Supplementary Materials). From Table 1 it can be seen that the particle size of the synthesized nanoparticles depends on the different metal precursor, reducing agent, and also the stabilizing agent. Figure 1 presented the amount of stable sample for silver and copper precursors, reducing 
agent, and stabilizer. Based on the experimental data it can be seen that in the case of silver precursor the high stability of colloidal solution had a silver citrate. In contrast, the sulfate and silver nitrate had a significantly less stability. The different correlation for copper precursor was observed. The copper nitrate and copper acetate showed the best stability compared to other precursors. In the case of reducing agent the highest stability was noticed for hydrazine. However, the most important aspect for the solution stability is a kind of stabilizer. It was observed that PVP had significantly better stabilizing and transparent properties for colloidal system. During the synthesis process for the reduction of silver and copper ions, three types of reducing agents were used, the strongest one, sodium borohydride $\left(\mathrm{NaBH}_{4}\right)$, and two weaker, hydrazine $\left(\mathrm{N}_{2} \mathrm{H}_{4}\right)$ and ascorbic acid $\left(\mathrm{C}_{6} \mathrm{H}_{8} \mathrm{O}_{6}\right)$. A twice excess of $\mathrm{NaBH}_{4}$ and $60 \%$ of the excess of $\mathrm{N}_{2} \mathrm{H}_{4}$ and $\mathrm{C}_{6} \mathrm{H}_{8} \mathrm{O}_{6}$ in relation to ions $\mathrm{Ag}^{+}$and $\mathrm{Cu}^{2+}$ were applied. Too low excess of a reducing agent caused only a partial reduction of the ions $\mathrm{Ag}^{+}, \mathrm{Cu}^{2+}$. However, at too high concentration of reducing agent, destabilization of the solution in a short time occurred. It was noticed that using $\mathrm{NaBH}_{4}$ for silver/copper solutions stabilized with PVP results in transparent, pale yellow solutions. The yellow color indicates the presence of the colloidal spherical particles [43]. It was observed that using a weaker reducing agent (hydrazine), in the synthesis of the silver nanoparticles, resulted in destabilization of a system. Only in the case of using silver citrate as the precursor Ag, a strong stabilizer of PVP, and a weaker reducing agent $\left(\mathrm{N}_{2} \mathrm{H}_{4}\right)$ it is possible to obtain a stable, transparent colloidal system. It is postulated because of an association with a stabilization of ions derived from ions citrate of metal precursor. The average size of obtained silver nanoparticles by reduction with hydrazine is in range between 215 and $395 \mathrm{~nm}$. The clear difference in particle size was observed for the same system with $\mathrm{NaBH}_{4}$ as the reducing agent. The average size of silver particles was about $40 \mathrm{~nm}$ and was even 10 times lower compared to nanoparticles obtained by $\mathrm{N}_{2} \mathrm{H}_{4}$ reducing agent.

A similar dependence was observed for the copper nanoparticles. When hydrazine was used as a reducing agent in PVP aqueous solution the diameter of obtaining silver particles was larger (ca. $262 \mathrm{~nm}$ ) than for sodium borohydride solution (ca. $20 \mathrm{~nm}$ ). From the point of view of stability and monodisperse of colloidal systems a really important parameter is the stabilizing agent type. For the preparation of nanoparticles, metal ions should be reduced in a colloid protective against precipitation. Moreover, the stable dispersions of nanoparticles are generally short-lived in aqueous media because they agglomerate to form larger clusters through Van der Waals forces between crystals [23].

Precipitation and agglomeration could be overcome through spontaneous adsorption of stabilizers on the particle surface. Additionally, charge, solubility, shape, and the size of obtained nanoparticles are determined by the type and concentration of the stabilizing agent [34, 44-50]. The amount of surfactant was regulated experimentally. To lower molar ratio of stabilizing substance to the salt of silver/copper caused insufficient coverage metal nanoparticles by stabilizer molecules resulting in excessive agglomeration. On the other hand when the concentration of stabilizer was really higher than the concentration of salt (molar ratio $50: 1$ ), the nanoparticles were not formed. Optimal dose of a stabilizer for the preparation of silver/copper nanoparticles was 1:10 molar ratio (salt:stabilizer). The similar observations were received by Dung Dang et al. [23]. They prepared colloidal copper nanoparticles with different molar ratio ions $\mathrm{Cu}^{2+}$ to PEG. After increasing the molar ratio from $1: 6$ to $1: 9\left(\mathrm{Cu}^{2+}: \mathrm{PEG}\right)$ the distribution size of colloidal copper particles tends to narrow while the mean diameter significantly decreases. Furthermore, aggregation seems to be diminished as well [23]. It clearly shows that the influence of the capping molecule concentration is crucial to the control of mean diameter and particle distribution size of expected nanoparticles. It was observed that all colloids stabilized with polyvinylpyrrolidone (PVP) were transparent, clear, and stable over three months. Application of citric acid, cetyltrimethylammonium bromide (CTAB), and polyethylene glycol (PEG) gave, for most the of samples, a suspension of aggregated particles. Systems were unstable after one day of storage. Chen and Yeh [39] stated that the nature of the surfactants affected the stability of the Ag particles. The silver nanoparticles can survive longer in anionic SDS than in cationic CTAB. They suggested that the stable colloid of silver cannot be reasonably applied to the CTAB surfactant, which has $-\mathrm{N}\left(\mathrm{CH}_{3}\right)^{3+}$ as the hydrophilic end. Instead of the $\mathrm{N}\left(\mathrm{CH}_{3}\right)^{3+}$ group, owing to electrostatic interaction, it is most likely that the CTAB hydrocarbon chains surround the Ag particles. The CTAB spherical micelles contain metal particles at or near the critical micelle concentration. Nevertheless, the CTAB-protected Ag particles seemed not sufficiently resistant to aggregation in this way [39].

If all the particles in suspension have a large negative or positive zeta potential, then they will tend to repel each other and there is no tendency to flocculate. However, if the particles have low zeta potential values, then there is no force to prevent the particles coming together and flocculating. The value of zeta potential is useful for understanding and predicting interactions between particles in suspension and this concept has been used to study a cell adhesion which in turn is related to surface charge properties [51]. The nanoparticles with negative zeta potential are stable due to the electrostatic repulsion as shown in Table 1 . It was observed that the stability of the colloidal silver and copper with the value of the zeta potential below $-20 \mathrm{mV}$ will result from steric stabilization of the particles by the macromolecular compounds as polyvinylpyrrolidone. Also, during the metal reduction, citrate and acetate ions are often used to offset the Van Der Waals forces among the particles by generating negative charge around NPs. Moreover, it was observed that PVP can significantly increase the absolute value of zeta potential of particle surfaces by electrostatic repulsions. PVP can introduce steric repulsion between nanoparticles, which is mainly attributed by the repulsion force generated by the steric configurations of PVP molecules [52]. Saeb et al. [53] stated that the particles with zeta potential values more positive than $+30 \mathrm{mV}$ or more negative than $-30 \mathrm{mV}$ are considered to be stable for the silver nanoparticles. Moreover, Du et al. [54] stated that the zeta potentials could be easily 

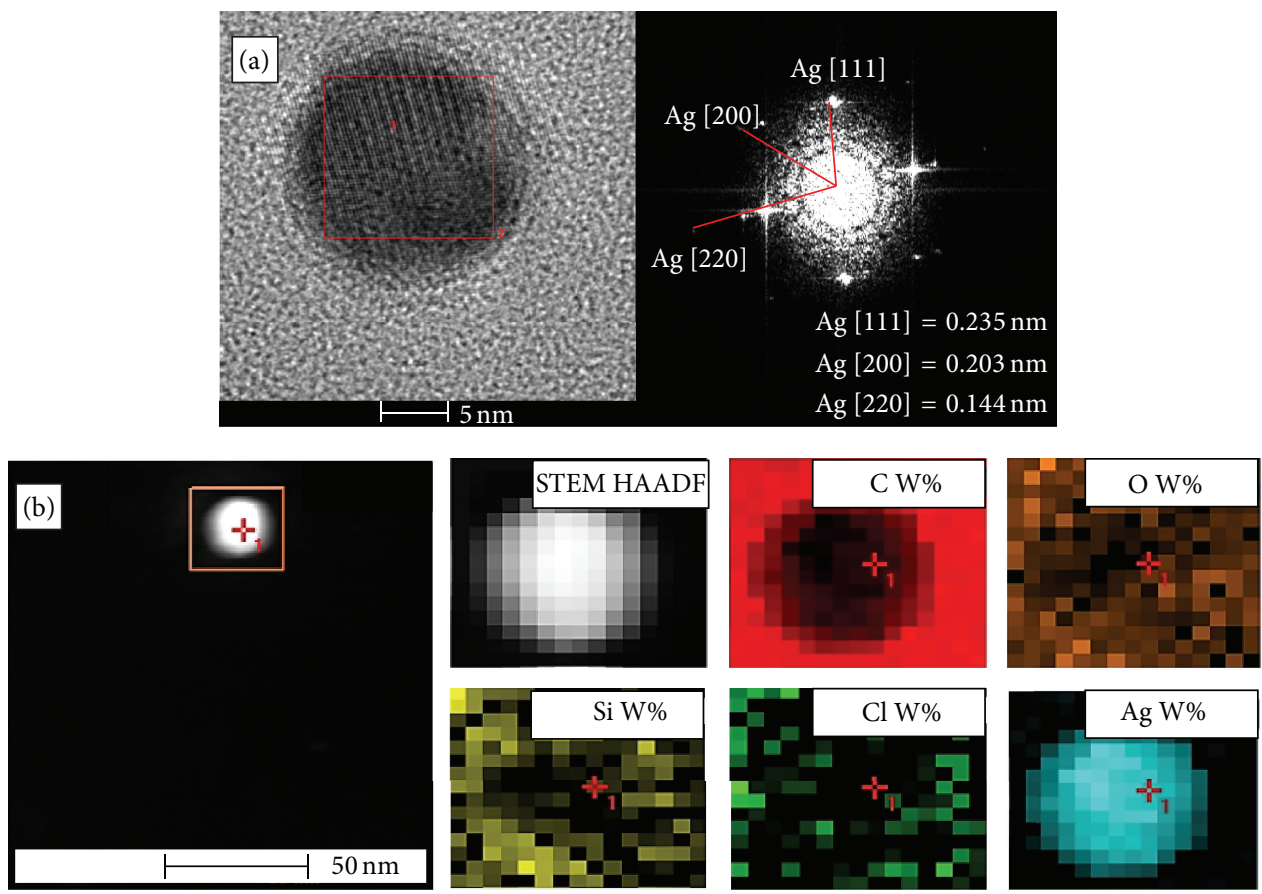

FIgURE 2: TEM images of obtained Ag NPs by chemical reduction method using silver citrate as a precursor, $\mathrm{NaBH}_{4}$ as a reducing agent, $\mathrm{PVP}$ as a stabilizer, and isopropanol and water $(3: 1)$ as a solvent. (a) SE mode and FFT plot and (b) point chemical analysis EDX.

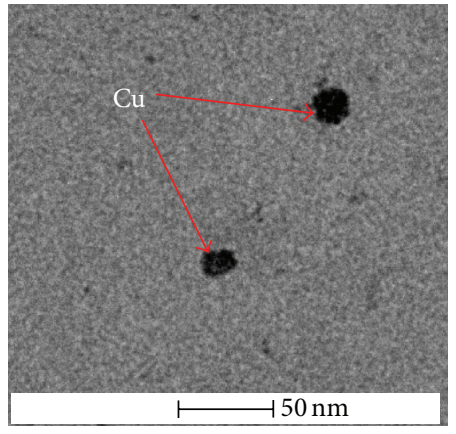

(a)

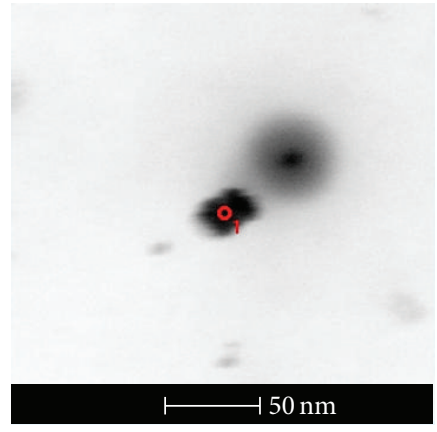

(b)

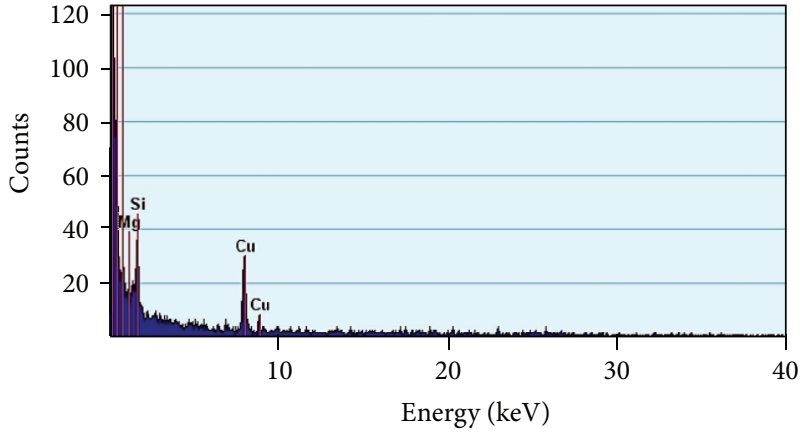

10.29.03 acquire EDX search HAADF point 2

(c)

FIGURE 3: TEM images of obtained $\mathrm{Cu}$ NPs by chemical reduction method using copper acetate as a precursor, $\mathrm{NaBH}_{4}$ as a reducing agent, PVP as a stabilizer, and isopropanol and water $(3: 1)$ as a solvent. (a) SE mode, (b) BF STEM mode, and (c) point chemical analysis EDX.

associated with the antibacterial activity. They suggested that an antibacterial activity was directly proportional to the zeta potential.

3.1.3. TEM Analysis. The most stable samples, in which there were no shape, aggregation, or dissolution changes observed, are recommended for microscopy studies. The composition of the metal nanoparticles for the stabile solution was studied using STEM (High Angle Annular Dark Field, HAADF) with EDXS mapping. The particles of silver were obtained by chemical reduction method using a silver citrate as a precursor, $\mathrm{NaBH}_{4}$ as a reducing agent, PVP as a stabilizer, and isopropanol and water $(3: 1)$ as a solvent. The average size of silver nanoparticles was about $15 \mathrm{~nm}$. Silver nanoparticles are spherical in shape as shown in Figure 2(a). The interplanar distances $d_{1}=0.235 \mathrm{~nm}, d_{2}=0.203 \mathrm{~nm}$, and $d_{3}=$ $0.144 \mathrm{~nm}$ from the Fast Fourier Transform (FFT) analysis of silver samples confirm the crystal plane (111), (220), and (222) of silver nanoparticles, respectively (see Figure 2(a)). The check by the color distribution of the EDXS maps and single measurements at different areas within one particle confirmed the presence of silver particles in the solution as shown in Figure 2(b). The blue spots were assigned to be Ag nanoparticles. In the case of copper nanoparticles the diameters of the observed nanoparticles were about $30 \mathrm{~nm}$. The structure of particles was confirmed by EDX mapping, presented in Figure 3. The main signal is derived from copper and the remaining scarce signals such as a silicon and 
TABLE 2: Preparation route and characteristics of bimetallic colloids.

\begin{tabular}{|c|c|c|c|c|}
\hline Sample label & Preparation route & $\begin{array}{l}\text { Structures } \\
\text { of metal }\end{array}$ & $\begin{array}{l}\text { LSPR, } \\
\lambda_{\max }\end{array}$ & $\begin{array}{l}\text { Color of } \\
\text { solution }\end{array}$ \\
\hline Alloy Ag/Cu & $\begin{array}{l}\mathrm{Ag}_{3} \mathrm{C}_{6} \mathrm{H}_{5} \mathrm{O}_{7}, \mathrm{C}_{4} \mathrm{H}_{6} \mathrm{O}_{4} \mathrm{Cu} \text { as precursors, single-step reduction with } \\
\mathrm{NaBH}_{4} \text {, stabilizer PVP }\end{array}$ & Alloy & $410 \mathrm{~nm}$ & Dark yellow \\
\hline Ag core/Cu shell & $\begin{array}{l}\mathrm{Ag}_{3} \mathrm{C}_{6} \mathrm{H}_{5} \mathrm{O}_{7}, \mathrm{C}_{4} \mathrm{H}_{6} \mathrm{O}_{4} \mathrm{Cu} \text { as precursors, double-step reduction with } \\
\mathrm{NaBH}_{4} \text {, stabilizer PVP }\end{array}$ & Core/shell & $408 \mathrm{~nm}$ & Yellow \\
\hline Cu core/Ag shell & $\begin{array}{l}\mathrm{C}_{4} \mathrm{H}_{6} \mathrm{O}_{4} \mathrm{Cu}, \mathrm{Ag}_{3} \mathrm{C}_{6} \mathrm{H}_{5} \mathrm{O}_{7} \text { as precursors, double-step reduction with } \\
\mathrm{NaBH}_{4} \text {, stabilizer PVP }\end{array}$ & Core/shell & $\begin{array}{l}413 \mathrm{~nm} \\
501 \mathrm{~nm}\end{array}$ & Light brown \\
\hline NPs $\mathrm{Cu} /$ ions $\mathrm{Ag}^{+}$ & $\begin{array}{l}\text { First solution: } \mathrm{Ag}_{3} \mathrm{C}_{6} \mathrm{H}_{5} \mathrm{O}_{7} \text {; second solution: } \mathrm{C}_{4} \mathrm{H}_{6} \mathrm{O}_{4} \mathrm{Cu} \text { as a precursor, } \\
\text { single-step reduction with } \mathrm{NaBH}_{4} \text {, stabilizer PVP; mixing of previously } \\
\text { prepared solutions ( } 1 \text { and } 2 \text { ) in volume ratio } 1: 1\end{array}$ & NPs/ions & $487 \mathrm{~nm}$ & Light brown \\
\hline NPs Ag/ions $\mathrm{Cu}^{2+}$ & $\begin{array}{l}\text { First solution: } \mathrm{C}_{4} \mathrm{H}_{6} \mathrm{O}_{4} \mathrm{Cu} \text {; second solution: } \mathrm{Ag}_{3} \mathrm{C}_{6} \mathrm{H}_{5} \mathrm{O}_{7} \text { as a precursor, } \\
\text { single-step reduction with } \mathrm{NaBH}_{4} \text {, stabilizer PVP; mixing of previously } \\
\text { prepared solutions ( } 1 \text { and } 2 \text { ) in volume ratio } 1: 1\end{array}$ & NPs/ions & $398 \mathrm{~nm}$ & Pale yellow \\
\hline
\end{tabular}

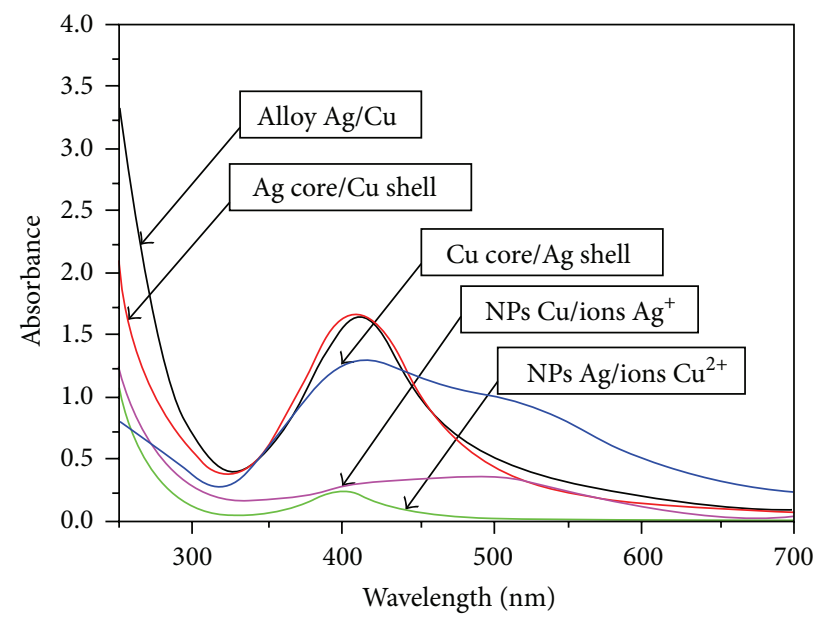

FIGURE 4: UV-Vis spectra of obtained bimetallic nanoparticles.

magnesium are derived from impurities in the sample. The $\mathrm{Cu}$ NPs are generally spherical.

3.2. Characteristic of Bimetallic Nanoparticles. The extensiveness of experimental studies on the synthesis parameters effect on the formation monometallic $\mathrm{Ag}$ and $\mathrm{Cu}$ NPs was demonstrated. Next, five of them were selected as the most stable composition of the bimetallic NPs. The operating conditions and the absorption properties of the obtained samples are shown in Table 2.

3.2.1. UV-Vis. The absorption spectrum of the UV-Vis for the solutions containing bimetallic nanoparticles of $\mathrm{Ag} / \mathrm{Cu}$ is shown in Figure 4. The effect of the particles structures is observed on the position and intensity of LSPR. The characteristic localized surface plasmon resonance (LSPR) bands maximum at $410 \mathrm{~nm}$ and $408 \mathrm{~nm}$ indicate that the contribution of $\mathrm{Ag}$ component is large in the $\mathrm{Ag}$ rich $\mathrm{Ag} / \mathrm{Cu}$ alloy and $\mathrm{Ag}$ (core)/Cu(shell), respectively. Taner et al. [55] revealed that silver NPs have a strong LSPR peak at $390 \mathrm{~nm}$ while that of the Ag/Cu NPs is red-shifted to $420 \mathrm{~nm}$. The author suggests that this displacement is due to the alloy structures creation of $\mathrm{Ag} / \mathrm{Cu}$ NPs. Navas and Soni [56] demonstrated that the position of the absorption band for the core-shell structures of the Ag/Cu particles depends on the thickness of the shell (copper). The LSPR peak of $\mathrm{Cu}$ in $\mathrm{Ag}-\mathrm{Cu}$ core-shell NPs is weak and appears only as a featureless absorption in a higher-wavelength region. A broad absorption band with two shoulders at about 413 and $501 \mathrm{~nm}$ was observed, suggesting that the bimetallic particles with $\mathrm{Cu}$ rich (core)-Ag rich (shell) structure are being formed. Previously, two plasmon bands at about $410 \mathrm{~nm}$ and second one from 525 to $580 \mathrm{~nm}$ were observed for $\mathrm{Cu} / \mathrm{Ag}$ bimetallic core-shell nanoparticles by Trinh et al. [57]. They found out that the absorption peak is shifted to longer wavelengths, closer to the absorption peak position of $\mathrm{Cu}$ oxide. In the case of sample with Ag NPs/ions $\mathrm{Cu}$ a single peak with a maximum in $398 \mathrm{~nm}$ was observed, attributable to LSPR of silver NPs. On the other hand, Cu NPs/ions Ag absorbing a longer wavelength $(>450 \mathrm{~nm})$ light indicate the presence of cooper particles. The main LSPR peaks (ca. $484 \mathrm{~nm}$ ) were observed for $\mathrm{Cu}$ NPs/ions Ag.

3.2.2. TEM Analysis. The morphology of the bimetallic NPs was studied using Cs-corrected STEM (High Angle Annular Dark Field, HAADF) with EDXS mapping. Therefore, it is possible to get images in a high resolution with $\mathrm{z}$-contrast based on the elastic scattering of the primary beam with the sample. This is an advantage especially in the case to detect bimetallic NPs internal structures like core/shell structures, fluctuations in composition within particles, and so on which are often invisible in conventional TEM. The structure of the bimetallic nanoparticles depends on the procedure route (sequencing of metal and reduction stages). Figures 5, 6, and 7 show the TEM images of the bimetallic combination in which the metals are introduced into the system simultaneously and next reduced step. The uniform distribution of silver and copper is observed which corresponds to the alloy structure of NPs, as shown in Figure 5. The EDX mapping also confirmed that $\mathrm{Ag}$ and $\mathrm{Cu}$ signal occurred in the same area. Metals were well-mixed in its composition. The average size of $\mathrm{Ag} / \mathrm{Cu}$ nanoparticles differs from 45 to $50 \mathrm{~nm}$. The shape of obtained $\mathrm{Ag} / \mathrm{Cu}$ bimetallic NPs was close to spherical as shown in Figures 5 and 6. 

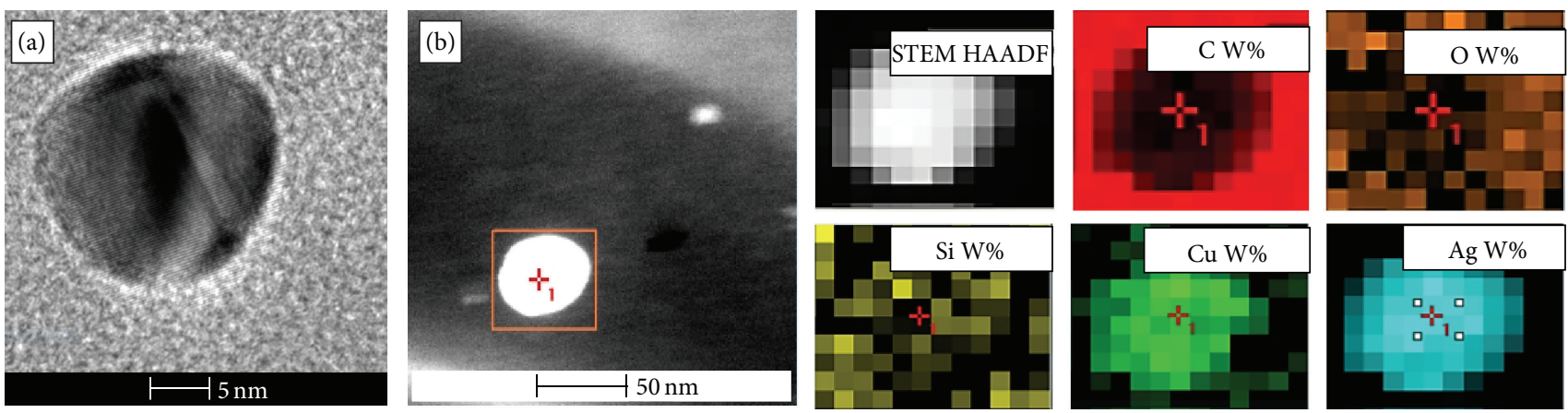

FIgURE 5: TEM images of obtained bimetallic alloy Ag/Cu nanoparticles. (a) SE mode and (b) point chemical analysis EDX.
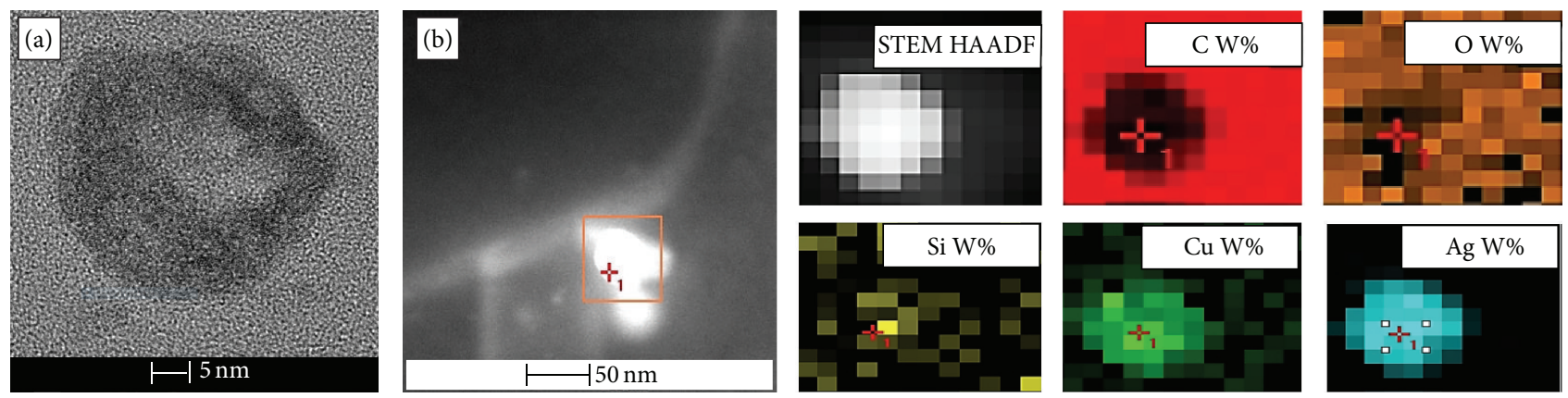

FIGURE 6: TEM images of obtained bimetallic Cu core/Ag shell nanoparticles. (a) SE mode and (b) point chemical analysis EDX.
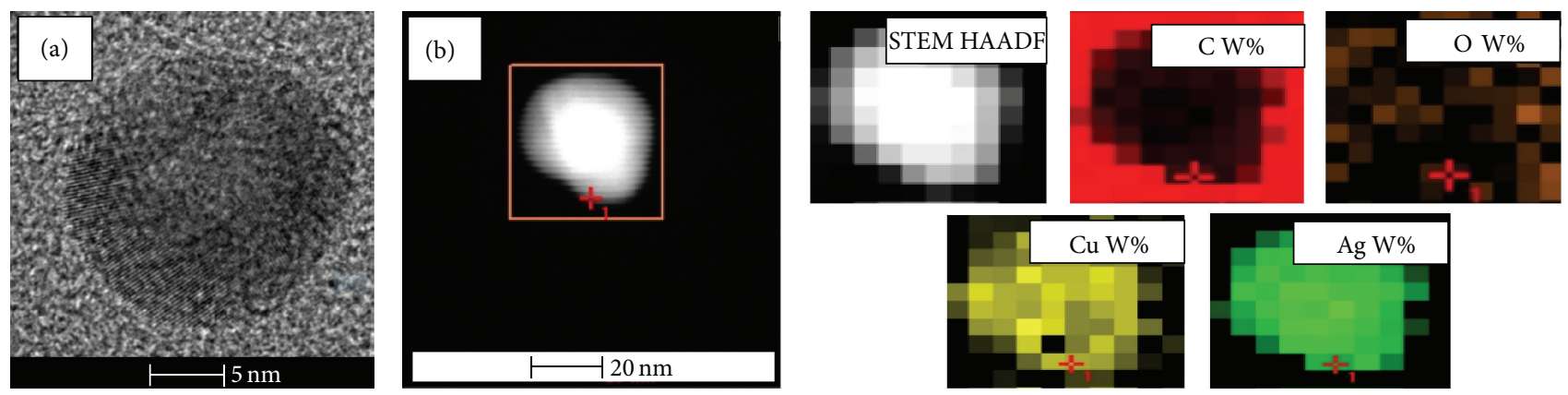

FIGURE 7: TEM images of obtained bimetallic Ag core/Cu shell nanoparticles. (a) SE mode and (b) point chemical analysis EDX.

The bimetallic particles size is in the range between 35 and $40 \mathrm{~nm}$. Based on the EDX mapping it could be observed that the core of bimetallic NPs was rich in cooper. However, the shell mostly contained silver.

In the case of a sample where the silver and copper were introduced first and two-step reduction was used core (rich in $\mathrm{Ag}$ )-shell (rich in $\mathrm{Cu}$ ) structure was observed. The EDX spectra clearly indicated that the silver content is higher than a copper content in NPs core, while the shell of NPs region was rich in copper as shown in Figure 7. The particle size and morphology can be modified due to the concentration change of reducing agent and stabilizer. The strongest reducing agent produced larger particles [58].

3.3. Assessment of Antibacterial Activity. The antibacterial and antifungal effect of functionalized samples was tested according to the Japanese Industrial Standard JIS L Standard 1902:2002. This method is based on the quantitative determination of the potential effect and activity of functionalized samples, by the direct contact with a suspension of bacterial cells. This study was used as inoculum of a strain of Escherichia coli ATCC 8739, Candida albicans ATCC 10231, and Staphylococcus aureus ATCC 6538. The cotton-synthetic fabric was modified with $\mathrm{Ag}$ and $\mathrm{Cu}$ which was characterized by the highest stability (see details in Table 3 , testing for antibacterial activity and efficiency on textile products (JIS L 1902:2002)). The results of the bioactivity investigations are presented in Table 3. The five samples showed a bacteriostatic activity and also a bactericidal activity against Escherichia coli and Staphylococcus aureus was found. However, these samples indicated the lowest fungicidal properties. The correlation between antibacterial properties and structures of bimetallic 
TABLE 3: The antibacterial and antifungal activity of selected $\mathrm{Ag}$ and $\mathrm{Cu}$ based colloidal solutions immobilized at cotton-synthetic fabric. The static activity was determined in accordance with the following equation: $S=M_{b}-M_{c}$ (see details in Section 2). The lethal activity was determined in accordance with the following equation: $L=M_{a}-M_{c}$ (see details in Section 2).

\begin{tabular}{|c|c|c|c|}
\hline Bacterial strain & $\begin{array}{l}\text { Candida albicans } \\
\text { ATCC } 10231\end{array}$ & $\begin{array}{l}\text { Escherichia coli } \\
\text { ATCC } 8739\end{array}$ & $\begin{array}{c}\text { Staphylococcus aureus } \\
\text { ATCC } 6538\end{array}$ \\
\hline Inoculum concentration (cell/mL) & $0.9 \pm 0.15 \times 10^{5}$ & $1.3 \pm 0.1 \times 10^{5}$ & $1.8 \pm 0.15 \times 10^{5}$ \\
\hline Value of growth $(F)$ & 1.51 & 1.51 & 1.54 \\
\hline The method of calculating the number of viable microorganisms & \multicolumn{3}{|c|}{ Plate method } \\
\hline Type of fabric & \multicolumn{3}{|c|}{ Cotton-synthetic fabric } \\
\hline & \multicolumn{3}{|c|}{ The static activity $(S) /$ lethal $(L)$} \\
\hline NanoAg 94 & $0.21 /-1.27$ & Absence* & Absence \\
\hline NanoCu 222 & $0.54 /-0.94$ & $0.31 /-1.20$ & $-0.01 /-1.55$ \\
\hline Alloy $\mathrm{Ag} / \mathrm{Cu}$ & $-0.02 /-1.50$ & Absence & Absence \\
\hline $\mathrm{Ag}$ core/Cu shell & $0.09 /-1.39$ & Absence & Absence \\
\hline $\mathrm{Cu}$ core/Ag shell & $0.46 /-1.02$ & $0.03 /-1.47$ & $0.03 /-1.50$ \\
\hline NPs Cu/ions $\mathrm{Ag}^{+}$ & $0.18 /-1.30$ & Absence & Absence \\
\hline NPs Ag/ions $\mathrm{Cu}^{2+}$ & $-0.05 /-1.43$ & Absence & Absence \\
\hline
\end{tabular}

Absence ${ }^{*}$ means the complete elimination of microorganisms. Sample is active microbiologically.

particles was observed. One of the textiles modified with $\mathrm{Cu}$ (core)-Ag (shell) particles tested did not have an antibacterial activity, whereas the bimetallic particles with alloy structures represent a very high antimicrobial activity. These different antibacterial properties may stem from various structures of bimetallic particles. The metals in bimetallic NPs are wellmixed and form the alloy composition. Their interaction of metals affects the enhanced antimicrobial properties. In the case of core-shell structure important parameter was the metal atoms location in NPs. However, the interaction of metals in the core-shell structure was significantly lower compared to the alloy structure and consequently affected antimicrobial properties. Hans et al. [59] stated that the $\mathrm{Cu}-\mathrm{Ag}$ alloy particles, compared to the pure elements, exhibited enhanced killing of Escherichia coli. It was observed that the nanoparticles monometallic bactericidal activity was dependent on the particle size. Silver NPs (ca. $15 \mathrm{~nm}$ ) have the bactericidal effects resulting not only in inhibition of bacterial growth but also in killing the bacteria. In copper NPs (ca. $30 \mathrm{~nm}$ ), there was no high bactericidal activity. The smaller particles which have a larger surface area available for interaction will give more bactericidal effect than the larger particles $[28,60]$. Zhang et al. [61] stated that the silver-treated cotton fabric showed $99.01 \%$ bacterial reduction of Staphylococcus aureus and $99.26 \%$ bacterial reduction of Escherichia coli while the silver content on cotton was about $88 \mathrm{mg} / \mathrm{kg}$. The cotton fabric was treated with nanosilver colloid by an impregnation method to provide the cotton fabric with antibacterial properties.

\section{Conclusions}

In this paper we presented the experimental studies concerning the effect of the synthesis parameters on the formation of monometallic $\mathrm{Ag}$ and $\mathrm{Cu}$ NPs. Here, we consider the synthesis strategies verification for the bimetallic core-shell and alloy particles preparation. It was observed that all colloids stabilized with polyvinylpyrrolidone (PVP) were transparent, clear, and stable for over three months. The application of citric acid, cetyltrimethylammonium bromide (CTAB), and polyethylene glycol (PEG) gave, for the most samples, a suspension of aggregated particles. It was observed that the stability of the colloidal silver and copper with the value of the zeta potential below $-20 \mathrm{mV}$ will result from steric stabilization of the particles by the macromolecular compounds as PVP. Also, during the metal reduction, the citrate and acetate ions are often used to offset the Van Der Waals forces among particles by generating a negative charge around NPs. Moreover it was observed that PVP can significantly increase by electrostatic repulsion to the absolute particle surfaces zeta potential value. This paper gives a comprehensive overview of the experimental studies which is concerned with the selection of the most stable colloidal solutions to impregnate fabrics that will exhibit the bactericidal and fungicidal activity. In this way, the effect of the type of bimetallic nanoparticles structures has been synthesized the first time in the literature and the applications have been investigated.

\section{Conflict of Interests}

The authors declare that there is no conflict of interests regarding the publication of this paper.

\section{Acknowledgment}

This research was financially supported by European Union in Project Eko-Styl Sp. Z o. o. company, "Gaining the Necessary Knowledge to Develop an Innovative Technology of Textiles Impregnation", no. WND-RPPK.01.03.00-18043/13. 


\section{References}

[1] M. J. Hajipour, K. M. Fromm, A. Akbar Ashkarran et al., "Antibacterial properties of nanoparticles," Trends in Biotechnology, vol. 30, no. 10, pp. 499-511, 2012.

[2] M. Rai, A. Yadav, and A. Gade, "Silver nanoparticles as a new generation of antimicrobials," Biotechnology Advances, vol. 27, no. 1, pp. 76-83, 2009.

[3] B. H. Patel and D. P. Chattopadhyay, "Preparation, characterization and stabilization of nanosized copper particles," International Journal of Pure and Applied Sciences and Technology, vol. 9, no. 1, pp. 1-8, 2012.

[4] N. R. Kim, K. Shin, I. Jung, M. Shim, and H. M. Lee, "Ag-Cu bimetallic nanoparticles with enhanced resistance to oxidation: a combined experimental and theoretical study," The Journal of Physical Chemistry C, vol. 118, no. 45, pp. 26324-26331, 2014.

[5] J. Sopoušek, J. Pinkas, P. Brož et al., "Ag-Cu colloid synthesis: bimetallic nanoparticle characterisation and thermal treatment," Journal of Nanomaterials, vol. 2014, Article ID 638964 , 13 pages, 2014.

[6] A. Sarkar, T. Mukherjee, and S. Kapoor, "PVP-stabilized copper nanoparticles: a reusable catalyst for 'click' reaction between terminal alkynes and azides in nonaqueous solvents," The Journal of Physical Chemistry C, vol. 112, no. 9, pp. 3334-3340, 2008.

[7] M. Kidwai, N. K. Mishra, V. Bansal, A. Kumar, and S. Mozumdar, "Cu-nanoparticle catalyzed O-arylation of phenols with aryl halides via Ullmann coupling," Tetrahedron Letters, vol. 48, no. 50, pp. 8883-8887, 2007.

[8] Y. Cheng, F. Wang, C. Fang, J. Su, and L. Yang, "Preparation and characterization of size and morphology controllable silver nanoparticles by citrate and tannic acid combined reduction at a low temperature," Journal of Alloys and Compounds, vol. 658, pp. 684-688, 2016.

[9] H. Wang, X. Qiao, J. Chen, and S. Ding, "Preparation of silver nanoparticles by chemical reduction method," Colloids and Surfaces A: Physicochemical and Engineering Aspects, vol. 256, no. 2-3, pp. 111-115, 2005.

[10] K. C. Song, S. M. Lee, T. S. Park, and B. S. Lee, "Preparation of colloidal silver nanoparticles by chemical reduction method," Korean Journal of Chemical Engineering, vol. 26, no. 1, pp. 153155, 2009.

[11] M. Starowicz, B. Stypuła, and J. Banaś, "Electrochemical synthesis of silver nanoparticles," Electrochemistry Communications, vol. 8, no. 2, pp. 227-230, 2006.

[12] R. A. Khaydarov, R. R. Khaydarov, O. Gapurova, Y. Estrin, and T. Scheper, "Electrochemical method for the synthesis of silver nanoparticles," Journal of Nanoparticle Research, vol. 11, no. 5, pp. 1193-1200, 2009.

[13] B. Yin, H. Ma, S. Wang, and S. Chen, "Electrochemical synthesis of silver nanoparticles under protection of poly $(N$ vinylpyrrolidone)," The Journal of Physical Chemistry B, vol. 107, pp. 8898-8904, 2003.

[14] A. Henglein, "Colloidal silver nanoparticles: photochemical preparation and interaction with $\mathrm{O}_{2}, \mathrm{CCl}_{4}$, and some metal ions," Chemistry of Materials, vol. 10, no. 1, pp. 444-450, 1998.

[15] K. Mallick, M. J. Witcomb, and M. S. Scurrell, "Polymer stabilized silver nanoparticles: a photochemical synthesis route," Journal of Materials Science, vol. 39, no. 14, pp. 4459-4463, 2004.

[16] J. Saade and C. B. de Araújo, "Synthesis of silver nanoprisms: a photochemical approach using light emission diodes," Materials Chemistry and Physics, vol. 148, no. 3, pp. 1184-1193, 2014.
[17] Z. Zhanjiang and L. Jinpei, "Synthesis and characterization of silver nanoparticles by a sonochemical method," Rare Metal Materials and Engineering, vol. 41, no. 10, pp. 1700-1705, 2012.

[18] S. Hojaghani, K. Akhbari, M. H. Sadr, and A. Morsali, "Sonochemical syntheses of one-dimensional silver(I) supramolecular polymer: a precursor for preparation of silver nanostructure," Inorganic Chemistry Communications, vol. 44, pp. 1-5, 2014.

[19] M. Darroudi, A. Khorsand Zak, M. R. Muhamad, N. M. Huang, and M. Hakimi, "Green synthesis of colloidal silver nanoparticles by sonochemical method," Materials Letters, vol. 66, no. 1, pp. 117-120, 2012.

[20] M. Valverde-Alva, T. García-Fernández, M. Villagrán-Muniz et al., "Synthesis of silver nanoparticles by laser ablation in ethanol: a pulsed photoacoustic study," Applied Surface Science, vol. 355, pp. 341-349, 2015.

[21] N. Ravi Chandra Raju, K. Jagadeesh Kumar, and A. Subrahmanyam, "Physical properties of silver oxide thin films by pulsed laser deposition: effect of oxygen pressure during growth," Journal of Physics D: Applied Physics, vol. 42, no. 13, Article ID 135411, 2009.

[22] E. Fazio, F. Neri, P. M. Ossi, N. Santo, and S. Trusso, "Growth process of nanostructured silver films pulsed laser ablated in high-pressure inert gas," Applied Surface Science, vol. 255, no. 24, pp. 9676-9679, 2009.

[23] T. M. Dung Dang, T. T. T. Le, E. Fribourg-Blanc, and M. Chien Dang, "The influence of solvents and surfactants on the preparation of copper nanoparticles by a chemicalreduction method," Advances in Natural Sciences: Nanoscience and Nanotechnology, vol. 2, no. 2, Article ID 025004, 2011.

[24] Y. Liu, S. Wei, and W. Gao, "Ag/ZnO heterostructures and their photocatalytic activity under visible light: effect of reducing medium," Journal of Hazardous Materials, vol. 287, pp. 59-68, 2015.

[25] B. Pant, P. Pokharel, A. P. Tiwari et al., "Characterization and antibacterial properties of aminophenol grafted and Ag NPs decorated graphene nanocomposites," Ceramics International, vol. 41, no. 4, pp. 5656-5662, 2015.

[26] Y. Sun and Y. Xia, "Shape-controlled synthesis of gold and silver nanoparticles," Science, vol. 298, no. 5601, pp. 2176-2179, 2002.

[27] D. P. Chattopadhyay and B. H. Patel, "Improvement in physical and dyeing properties of natural fibres through pre-treatment with silver nanoparticles," Indian Journal of Fibre and Textile Research, vol. 34, no. 4, pp. 368-373, 2009.

[28] J. P. Ruparelia, A. K. Chatterjee, S. P. Duttagupta, and S. Mukherji, "Strain specificity in antimicrobial activity of silver and copper nanoparticles," Acta Biomaterialia, vol. 4, no. 3, pp. 707-716, 2008.

[29] L. A. Tamayo, P. A. Zapata, N. D. Vejar et al., "Release of silver and copper nanoparticles from polyethylene nanocomposites and their penetration into Listeria monocytogenes," Materials Science and Engineering C, vol. 40, pp. 24-31, 2014.

[30] M. Li, L. Nan, D. Xu, G. Ren, and K. Yang, "Antibacterial performance of a Cu-bearing stainless steel against microorganisms in tap water," Journal of Materials Science \& Technology, vol. 31, no. 3, pp. 243-251, 2015.

[31] J. Liu, F. Li, C. Liu et al., "Effect of Cu content on the antibacterial activity of titanium-copper sintered alloys," Materials Science and Engineering C, vol. 35, no. 1, pp. 392-400, 2014.

[32] M. Tsuji, S. Hikino, R. Tanabe, M. Matsunaga, and Y. Sano, "Syntheses of $\mathrm{Ag} / \mathrm{Cu}$ alloy and $\mathrm{Ag} / \mathrm{Cu}$ alloy core $\mathrm{Cu}$ shell 
nanoparticles using a polyol method," CrystEngComm, vol. 12, no. 11, pp. 3900-3908, 2010.

[33] N. M. Zain, A. G. F. Stapley, and G. Shama, "Green synthesis of silver and copper nanoparticles using ascorbic acid and chitosan for antimicrobial applications," Carbohydrate Polymers, vol. 112, pp. 195-202, 2014.

[34] C. K. Kim, G.-J. Lee, M. K. Lee, and C. K. Rhee, "A novel method to prepare $\mathrm{Cu@Ag} \mathrm{core-shell} \mathrm{nanoparticles} \mathrm{for} \mathrm{printed} \mathrm{flexible}$ electronics," Powder Technology, vol. 263, pp. 1-6, 2014.

[35] A. P. Gomes, J. F. Mano, J. A. Queiroz, and I. C. Gouveia, "Layerby-layer deposition of antimicrobial polymers on cellulosic fibers: a new strategy to develop bioactive textiles," Polymers for Advanced Technologies, vol. 24, no. 11, pp. 1005-1010, 2013.

[36] P. B. Price, "The meaning of bacteriostasis, bactericidal effect, and rate of disinfection," Annals of The New York Academy of Sciences, vol. 53, pp. 76-90, 1950.

[37] A. Zielińska, E. Skwarek, A. Zaleska, M. Gazda, and J. Hupka, "Preparation of silver nanoparticles with controlled particle size," Procedia Chemistry, vol. 1, no. 2, pp. 1560-1566, 2009.

[38] S. Eustis and M. A. El-Sayed, "Why gold nanoparticles are more precious than pretty gold: noble metal surface plasmon resonance and its enhancement of the radiative and nonradiative properties of nanocrystals of different shapes," Chemical Society Reviews, vol. 35, no. 3, pp. 209-217, 2006.

[39] Y.-H. Chen and C.-S. Yeh, "Laser ablation method: use of surfactants to form the dispersed Ag nanoparticles," Colloids and Surfaces A: Physicochemical and Engineering Aspects, vol. 197, no. 1-3, pp. 133-139, 2002.

[40] D. Philip, "Biosynthesis of $\mathrm{Au}, \mathrm{Ag}$ and $\mathrm{Au}-\mathrm{Ag}$ nanoparticles using edible mushroom extract," Spectrochimica Acta Part A: Molecular and Biomolecular Spectroscopy, vol. 73, no. 2, pp. 374381, 2009.

[41] D. O. Shin, J.-R. Jeong, T. H. Han et al., "A plasmonic biosensor array by block copolymer lithography," Journal of Materials Chemistry, vol. 20, no. 34, pp. 7241-7247, 2010.

[42] R. M. Tilaki, A. I. Zad, and S. M. Mahdavi, "Size, composition and optical properties of copper nanoparticles prepared by laser ablation in liquids," Applied Physics A, vol. 88, no. 2, pp. 415-419, 2007.

[43] R. Jin, Y. Cao, C. A. Mirkin, K. L. Kelly, G. C. Schatz, and J. G. Zheng, "Photoinduced conversion of silver nanospheres to nanoprisms," Science, vol. 294, no. 5548, pp. 1901-1903, 2001.

[44] E. J. Kim, J. H. Yeum, and J. H. Choi, "Effects of polymeric stabilizers on the synthesis of gold nanoparticles," Journal of Materials Science \& Technology, vol. 30, no. 2, pp. 107-111, 2014.

[45] W. P. Dunworth and F. F. Nord, "Noble metal-synthetic polymer catalysts and studies on the mechanism of their action," Advances in Catalysis, vol. 6, pp. 125-141, 1954.

[46] N. Toshima, M. Harada, Y. Yamazaki, and K. Asakura, "Catalytic activity and structural analysis of polymer-protected goldpalladium bimetallic clusters prepared by the simultaneous reduction of hydrogen tetrachloroaurate and palladium dichloride," Journal of Physical Chemistry, vol. 96, no. 24, pp. 99279933, 1992.

[47] H. H. Huang, X. P. Ni, G. L. Loy et al., "Photochemical formation of silver nanoparticles in poly( $N$-vinylpyrrolidone)," Langmuir, vol. 12, no. 4, pp. 909-912, 1996.

[48] C. Luo, Y. Zhang, X. Zeng, Y. Zeng, and Y. Wang, "The role of poly(ethylene glycol) in the formation of silver nanoparticles," Journal of Colloid and Interface Science, vol. 288, no. 2, pp. 444448, 2005.
[49] P.-L. Kuo, C.-C. Chen, and M.-W. Jao, "Effects of polymer micelles of alkylated polyethylenimines on generation of gold nanoparticles," Journal of Physical Chemistry B, vol. 109, no. 19, pp. 9445-9450, 2005.

[50] X. Sun, S. Dong, and E. Wang, “One-step synthesis and characterization of polyelectrolyte-protected gold nanoparticles through a thermal process," Polymer, vol. 45, no. 7, pp. 21812184, 2004.

[51] S. Singh, A. Bharti, and V. K. Meena, "Structural, thermal, zeta potential and electrical properties of disaccharide reduced silver nanoparticles," Journal of Materials Science: Materials in Electronics, vol. 25, no. 9, pp. 3747-3752, 2014.

[52] N. Saleh, K. Sirk, Y. Liu et al., "Surface modifications enhance nanoiron transport and NAPL targeting in saturated porous media," Environmental Engineering Science, vol. 24, no. 1, pp. 4557, 2007.

[53] A. T. M. Saeb, A. S. Alshammari, H. Al-Brahim, and K. A. Al-Rubeaan, "Production of silver nanoparticles with strong and stable antimicrobial activity against highly pathogenic and multidrug resistant bacteria," The Scientific World Journal, vol. 2014, Article ID 704708, 9 pages, 2014.

[54] W.-L. Du, S.-S. Niu, Y.-L. Xu, Z.-R. Xu, and C.-L. Fan, "Antibacterial activity of chitosan tripolyphosphate nanoparticles loaded with various metal ions," Carbohydrate Polymers, vol. 75, no. 3, pp. 385-389, 2009.

[55] M. Taner, N. Sayar, I. G. Yulug, and S. Suzer, "Synthesis, characterization and antibacterial investigation of silver-copper nanoalloys," Journal of Materials Chemistry, vol. 21, no. 35, pp. 13150-13154, 2011.

[56] M. P. Navas and R. K. Soni, "Laser-generated bimetallic Ag$\mathrm{Au}$ and $\mathrm{Ag}-\mathrm{Cu}$ core-shell nanoparticles for refractive index sensing," Plasmonics, vol. 10, no. 3, pp. 681-690, 2015.

[57] D. C. Trinh, T. M. D. Dang, K. K. Huynh, E. Fribourg-Blanc, and M. C. Dang, "Synthesis of $\mathrm{Cu}$ core Ag shell nanoparticles using chemical reduction method," Advances in Natural Sciences: Nanoscience and Nanotechnology, vol. 6, no. 2, Article ID 025018, 2015.

[58] A. Amany and S. F. G. El-Rab, "Effect of reducing and protecting agents on size of silver nanoparticles and their anti-bacterial activity," Der Pharma Chemica, vol. 4, no. 1, pp. 53-65, 2012.

[59] M. Hans, J. C. Támara, S. Mathews et al., "Laser cladding of stainless steel with a copper-silver alloy to generate surfaces of high antimicrobial activity," Applied Surface Science, vol. 320, pp. 195-199, 2014.

[60] A. Panáček, L. Kvítek, R. Prucek et al., "Silver colloid nanoparticles: synthesis, characterization, and their antibacterial activity," The Journal of Physical Chemistry B, vol. 110, no. 33, pp. 1624816253, 2006.

[61] F. Zhang, X. Wu, Y. Chen, and H. Lin, "Application of silver nanoparticles to cotton fabric as an antibacterial textile finish," Fibers and Polymers, vol. 10, no. 4, pp. 496-501, 2009. 

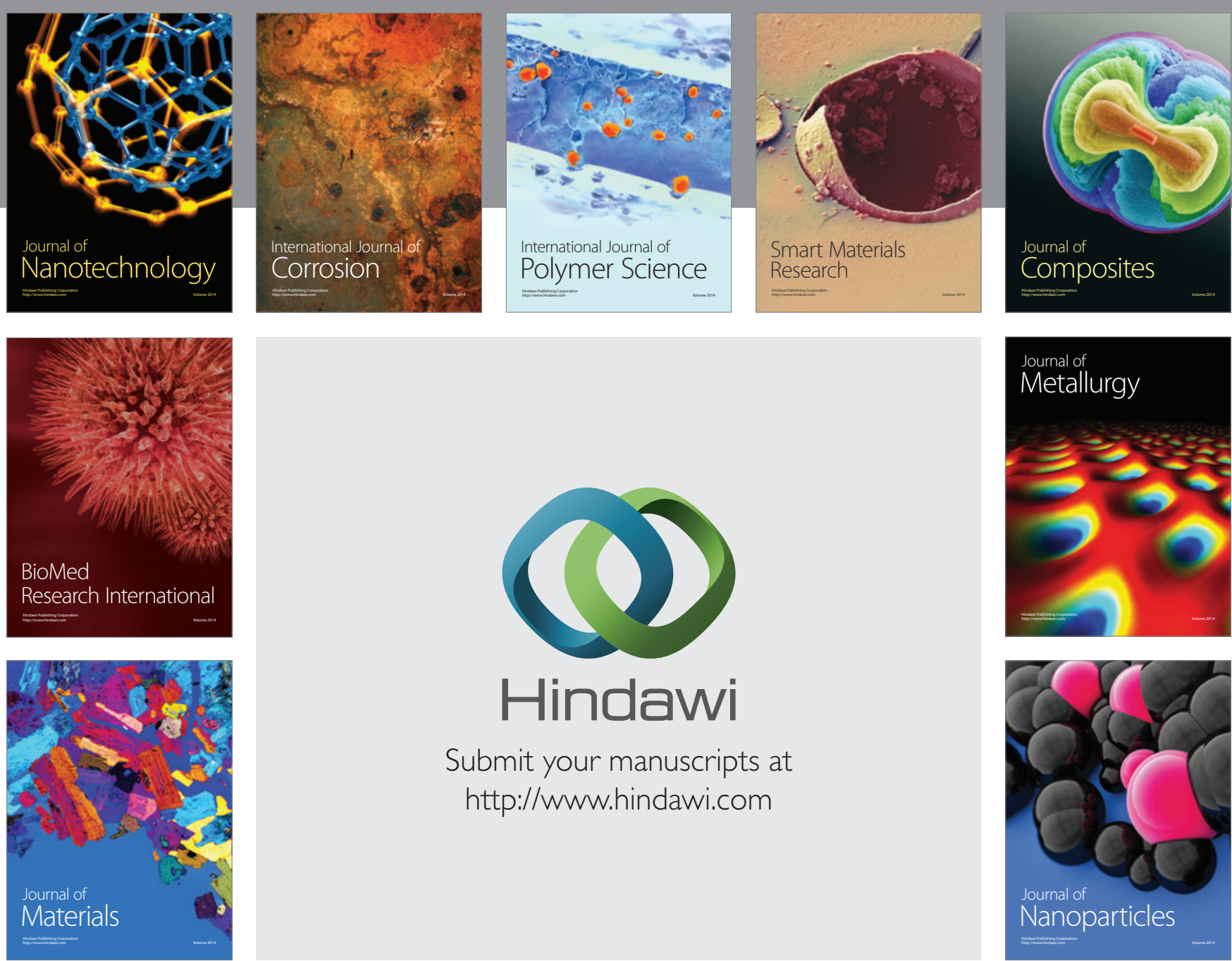

\section{Hindawi}

Submit your manuscripts at

http://www.hindawi.com

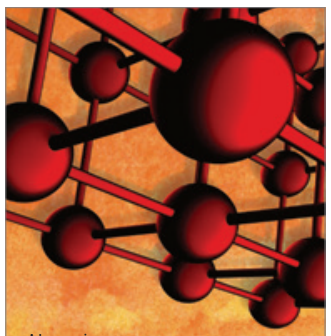

Materials Science and Engineering
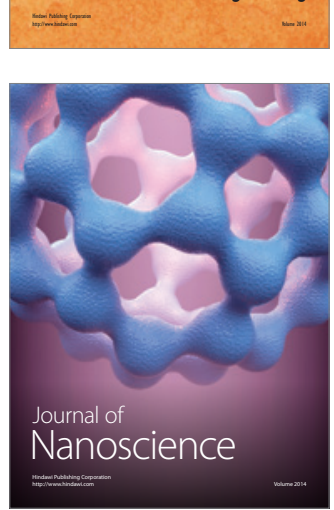
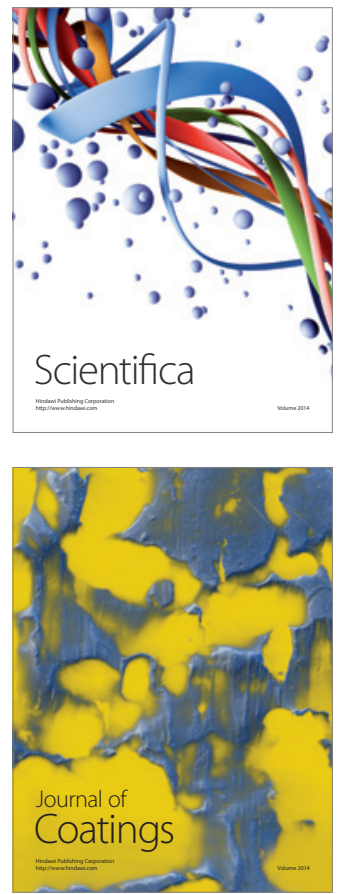
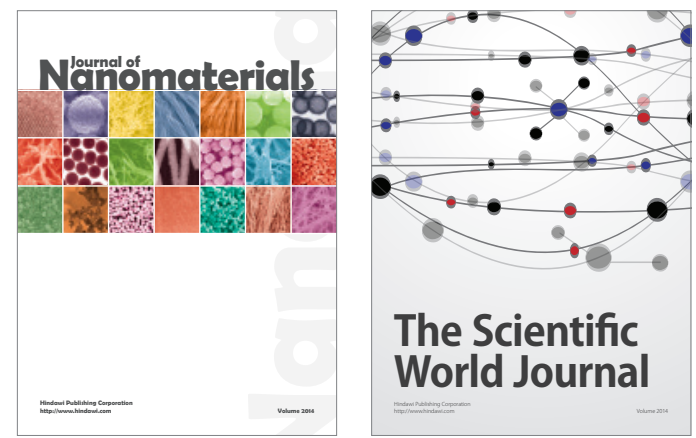

The Scientific World Journal
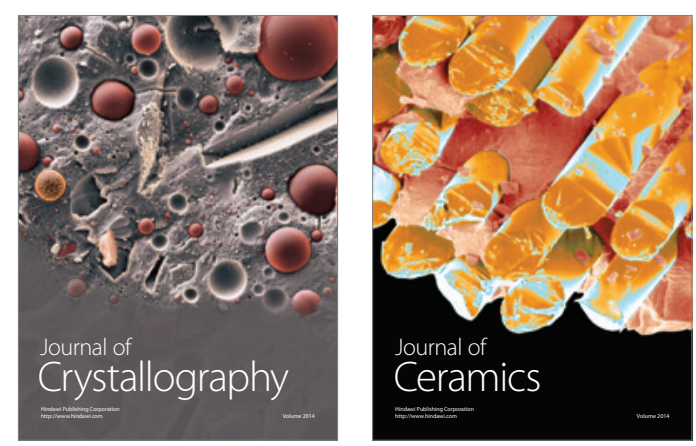
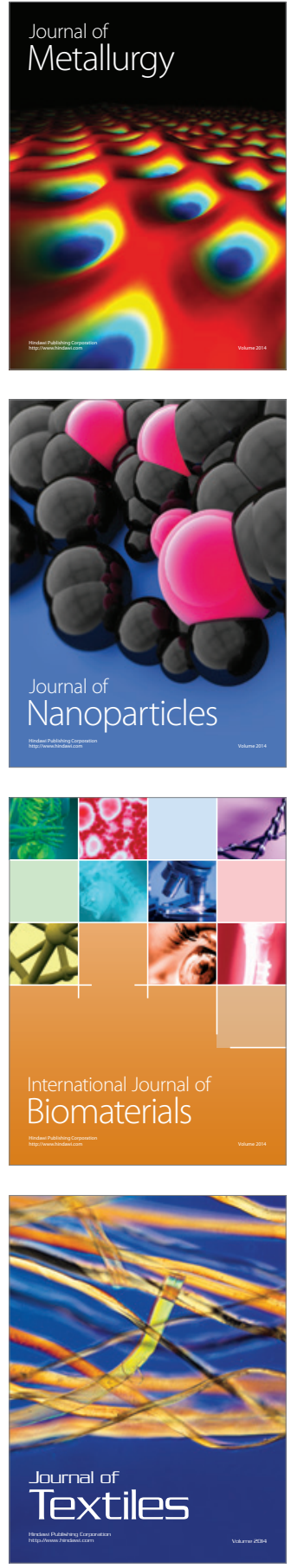